Article

\title{
Estimation of Clear Sky Normal Irradiance over Northern Nige- ria Atmosphere
}

\author{
Njoku E.I *, Arogbokun F.E \\ Department of Physics, University of Ibadan, Nigeria \\ *Correspondence: emmanuelnjoku123@gmail.com
}

How to cite this paper : E.I, N., \& F.E, A. (2021). Estimation of Clear Sky Normal Irradiance Over Northern Nigeria Atmosphere. Research Journal of Ecology and Environmental Sciences, 1(2), 96-107. Retrieved from https://www.scipublications.com/journal/index.php/rjees/article/view/123
Received: August 20, 2021 Accepted: October 6, 2021 Published: October 7, 2021

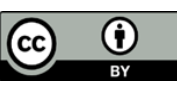

Copyright: (c) 2021 by the authors. Submitted for possible open access publication under the terms and conditions of the Creative Commons Attribution (CC BY) license (http://creativecommons.org/licenses /by/4.0/).
Abstract: Energy from the sun is an ideal new energy source for power systems, in a context of sustainable development, enthusiasm for concentrated solar power technologies is developing. Accurate estimation of clear-sky radiation is needed in many engineering, architectural and agricultural applications in order to integrate solar energy into the power grid. An evaluation of the irradiance input to solar power systems is required in many applications. Clear-sky models represent the maximum input of solar power systems, which is especially useful for forecasting solar irradiance and numerical weather prediction. This work examined the application of Yang model to estimate the monthly mean clear sky normal irradiance for northern Nigeria using meteorological variables like temperature, relative humidity and solar radiation considering the shading effect of the complex topography of terrain in Norther region of Nigeria, also to know the variation of beam radiation and diffuse radiation among the selected stations and also to ascertain the significance of aerosols, water vapor, and other transmittances in the estimation of the beam and diffuse radiation in the northern atmosphere. The modeling was computed using monthly mean maximum temperature and relative humidity gotten from the Nigeria Meteorological Agency (NIMET) for the period of fourteen years (1983-1997. The beam and diffuse irradiance for the northern atmosphere is compared by estimating their mean and standard deviation. Also, detailed information about the trend of radiation in each of the selected states in the northern hemisphere of Nigeria was obtained using a graphical method of data analysis. Result reveals that the value of beam and diffused radiation getting to the earth's surface depends on the aerosols, water vapour, atmospheric Ozone, gas transmittance and Rayleigh scattering. From the result above, the maximum beam radiation and the minimum diffused radiation occur during the raining season and the minimum beam radiation and maximum diffuse radiation occur during the dry season. This is due to the variations of these atmospheric constituents (aerosols, water vapour, atmospheric Ozone, gas transmittance and Rayleigh scattering) in the northern atmosphere on these seasons.

Keywords: Transmittance, Rayleigh Scattering, Yang Model, Clear sky, pyranometer, Radiometer or Solarimeter

\section{Introduction}

Incoming solar radiation, global or total radiation, or insolation is the amount of solar energy that reaches the earth's surface. It is made up of direct and diffused radiation and may be expressed in $\mathrm{MJm}^{-2} \mathrm{day}^{-1}$ on a horizontal surface or as an equivalent depth of evaporation per day in inches or $\mathrm{mm}$. It can be measured with pyranometer, radiometers or solarimeter.

The incoming radiant energy is converted into various forms (internal heat, potential energy, latent energy, and kinetic energy), and then moved around in various ways, primarily by the atmosphere and oceans, before being stored and sequestered in the ocean, land, and ice components of the climatic system, and ultimately radiated back to space as infrared radiation as shown in Figure 1 and Figure 2 
Solar radiation is diminished by scattering (due to air molecules and particles) and absorption processes as it travels through the earth's atmosphere (mainly by ozone, water vapor, oxygen, carbon dioxide and absorbing aerosols such as dust and smoke). Absorption takes place in lines and bands. The scattering occurs across the entire solar spectrum. Solar radiation receives at the earth's surface is of primary importance in a variety of fields. This includes climate studies, illumination engineering, the biophysical impact of atmospheric pollution, atmospheric physics, solar power and photovoltaic application, and remote sensing application.

Clear sky is a sky free of clouds, fogs or other obstructions. The clear sky is transparent to solar radiation at wavelengths of visible light in the visible range. The visible range scattering is done by molecule and aerosols particles, little absorption by aerosol particle, ozone and other trace gases [1]

The sun provides about $99.97 \%$ of the heat energy required for the physical processes taking place in the earth atmosphere system. Each minute, it radiates approximately 56× $10^{26}$ calories of energy. This radiation travels with a velocity of $3 \times 10^{8} \mathrm{~m} / \mathrm{s}$ taking approximately 9 minutes to reach the earth's atmosphere [2]. The solar constant's value (a term used to define the degree at which solar radiation is received outside the earth's atmosphere, at the mean distance of the earth from the sun) is $1.94 \mathrm{MJm}^{-2} \mathrm{~min}^{-1}$, and can vary by $\pm 3.4 \%$ during the year partly due to variations in the earth- sun distance[3].

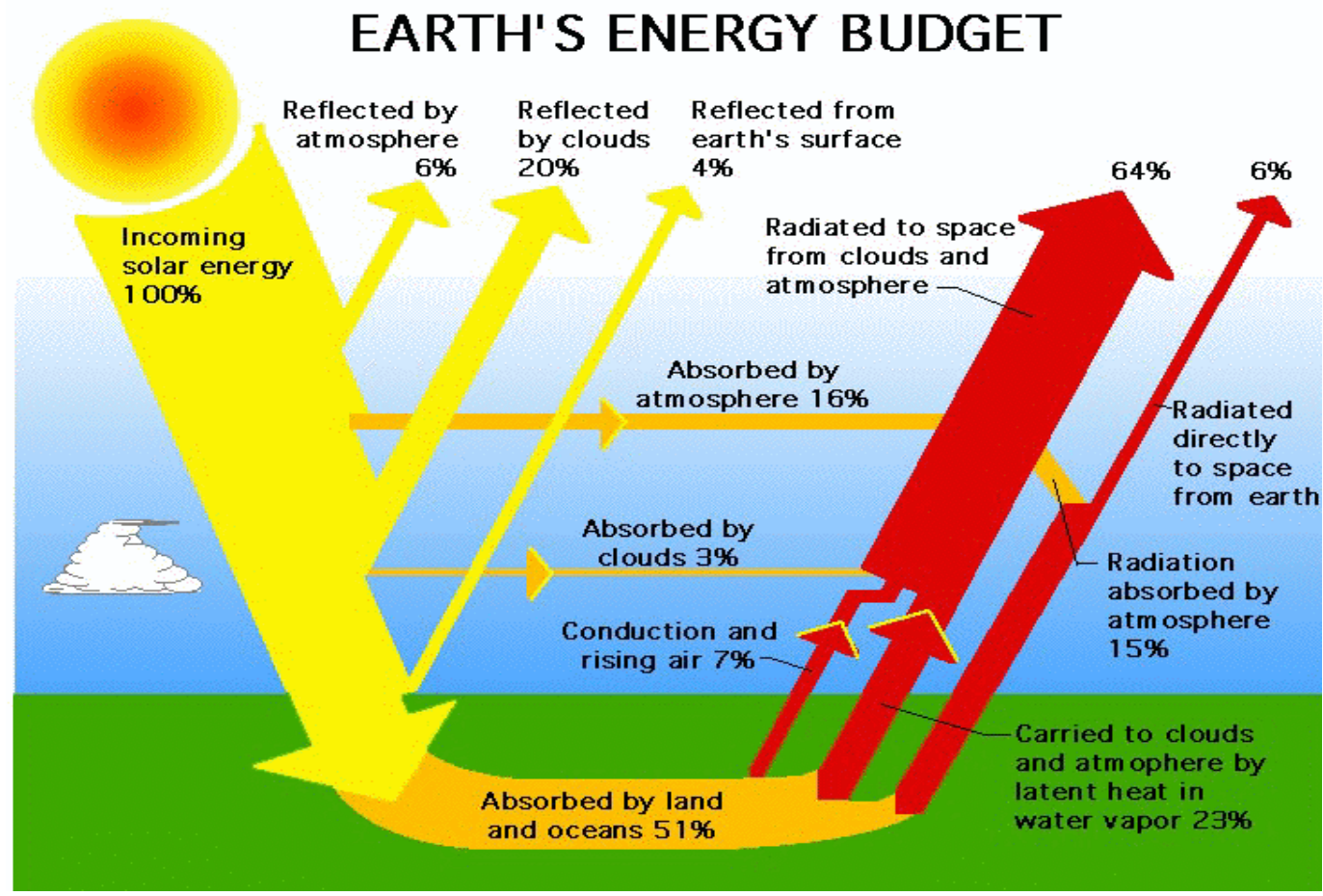

Figure 1. Earth's Energy budget (Source. Nasa. Atmospheric Science Data Center)

Several empirical models have been developed to calculate direct irradiance using various climatic parameters. Mean temperature, maximum temperature, soil temperature, relative humidity, number of wet days, height, latitude, total precipitation, and evaporation are some of the variables to be considered [4]

Over the years, many models have been proposed to predict the amount of direct solar irradiance using various parameters. [5] analyzed global index and diffuse fraction for clear-sky conditions using direct, global, and diffuse solar radiations (cloudless) taken over a one-year period at Helwan. In the absence of any other radiation measurements, the results underscore the requirement for routine instantaneous surface meteorological data to compute global and diffuse radiations on a horizontal surface. [6] calculate global 
solar radiation in a clear sky by using a damping spectrum. He considers the effect of latitude, elevation, and other factors in his model, but the simplification of the damping spectrum limits his work. Therefore, Yang simplify the Leckner damping spectrum and used it to calculate beam radiation and diffuse radiation. The outstanding performance of the Yang model was proven after comparing other models for the calculation of direct normal irradiance over Egypt's atmosphere [7]. [8] used a solar radiation model to investigate the efficacy of broadband direct irradiance predictions. He concluded that Yang is one of the high-performance models that can be recommended as a result of his detailed investigation. [9] estimated direct normal irradiance using Rayleigh transmittance, ozone transmittance, uniformly mixed gas transmittance, water vapor transmittance, and aerosol transmittance. [10] estimated direct irradiance by calculating link turbidity from solar elevation, precipitable water and turbidity.

[11] predicted direct normal irradiance from aerosol transmittance, water vapor and air mass without calculating separate atmospheric transmittances. He obtained direct normal irradiance as a function of the idea irradiance below an aerosol free atmosphere, [12] estimated the diffuse fraction using clearness index, $k \mathrm{t}$ (global irradiance/horizontal extraterrestrial irradiance) as the only variable. They used global and diffuse irradiance values registered in Toronto (Canada, $43.8^{\circ} \mathrm{N}$ ) to validate the model.

[13] used a hybrid model to estimate global solar radiation. He used two radiative transmittances. One is a clear sky transmittance, which is determined by local geographical and meteorological variables. The other is a cloud-related transmittance function based on hourly, daily, or monthly relative sunshine duration. Using a broadband radiative transfer model, he calculated solar beam radiative transmittance and solar diffuse radiative transmittance under the clear sky. Models that compute the decomposition of global irradiance into its components and models that calculate atmospheric transmittance are the two models that can be used to determine direct irradiance. Models of atmospheric transmittance require precise information on atmospheric factors like turbidity, precipitable water content, and cloud cover. Decomposition models, on the other hand, employ global irradiance data to estimate direct and diffuse irradiance. [14]

\section{Materials and Methods}

The monthly mean clear sky normal irradiance over the northern Nigerian atmosphere is estimated using monthly mean temperatures (minimum and maximum) and monthly mean relative humidity obtained from the archives of Nigeria Meteorological Agency (NIMET) for the period of fourteen years (1983-1997). The value of ozone thickness is a satellite data provided by NASA and GSFC. The surface pressure and precipitable water used in this study were calculated. The five stations being studied lie on the latitudes and longitudes stated in the Table 1 below.

Table 1. Latitude and longitude of the selected stations.

\begin{tabular}{ccc}
\hline Stations & Latitude $^{(0)}$ & Longitude( $\left.^{(}\right)$ \\
\hline Kano & $12.05^{\circ} \mathrm{N}$ & $8.26^{\circ} \mathrm{E}$ \\
Sokoto & $13.02^{\circ} \mathrm{N}$ & $5.25^{\circ} \mathrm{E}$ \\
Yola & $9.23^{\circ} \mathrm{N}$ & $12.47^{\circ} \mathrm{E}$ \\
Minna & $9.62^{\circ} \mathrm{N}$ & $6.53^{\circ} \mathrm{E}$ \\
Maiduguri & $11.85^{\circ} \mathrm{N}$ & $13.03^{\circ} \mathrm{E}$ \\
\hline
\end{tabular}

This study uses the yang model to predict and estimate the monthly mean clear sky normal irradiance for the northern atmosphere in Nigeria.

Yang used a broadband radiative transfer model to calculate solar beam radiative transmittance $T_{b \text { clear }}$ and solar diffuse radiative transmittance $T_{d}$ clear under clear skies. 


$$
\begin{gathered}
T_{b \text { clear }} \approx \max \left(0, T_{0 z} T_{w} T_{g} T_{r} T_{a}-0.013\right) \\
T_{d \text { clear }} \approx \max \left\{0,0.5\left[T_{0 z} T_{w} T_{g}\left(1-T_{r} T_{a}\right)+0.013\right]\right\} \\
T_{g}=\exp \left(-0.0117 \mathrm{~m}^{0.3139}\right) \\
T_{r}=\exp \left[-0.00873 \mathrm{~m}_{\mathrm{c}}\left(0.547+0.014 \mathrm{~m}_{c}+0.00038 m_{c}{ }^{2}+4.6 \times 10^{-6} m_{c}{ }^{3}\right)^{-4.08}\right] \\
T_{w}=\min [1.0,0.909-0.036 \ln (m w)] \\
T_{o z}=\exp \left[-0.0365(m l)^{0.7136}\right] \\
T_{a}=\exp \left\{-m \beta\left[0.6777+0.1464(m \beta)-0.00626(m \beta)^{2}\right]\right\} \\
m=1 /\left[\sin h+0.15(57.296 h+3.885)^{-1.253}\right] \\
m_{c}=m p_{s} / p_{o}
\end{gathered}
$$

Where $T_{g}$ is radiative transmittances due to permanent gas absorption, $T_{r}$ is radiative transmittances due to Rayleigh scattering, $T_{w}$ is radiative transmittances due to water vapour absorption, $T_{o z}$ is radiative transmittances due to ozone absorption, $T_{a}$ is radiative transmittances due to aerosols extinction, $\mathrm{m}$ is the air mass, $\mathrm{m}_{\mathrm{c}}$ is the pressure corrected air mass, $\mathrm{p}_{\mathrm{s}}$ is the surface pressure, $\mathrm{p}_{\mathrm{o}}$ is the standard atmospheric pressure, $\mathrm{h}$ is the solar elevation, $\beta$ is the angstrom turbidity, and $\mathrm{w}$ is the precipitable water.

In this study, the value of surface pressure $\left(\mathrm{P}_{\mathrm{s}}\right)$, precipitable water $(\mathrm{w})$ and angstrom turbidity $(\beta)$, is estimated by equation (3.10-3.12). The value of relative humidity and temperature is obtained from the achieves of Nigeria Meteorological Agency (NIMET) while the value of aerosol optical depth is obtained from GADS (Global Distribution of Aerosols Data Set)

$$
\begin{aligned}
P_{S} & =p_{0} \exp (-\mathrm{z} / \mathrm{HT}) \\
\mathrm{w} & =0.00493 \mathrm{hr}_{\mathrm{r}} \mathrm{Ta}^{-1} \exp \left[26.23-5416 \mathrm{Ta}_{\mathrm{a}}^{-1}\right] \\
\beta & =0.55^{1.3} \delta(0.5)
\end{aligned}
$$

Where $\mathrm{p}_{0}=1.013 \times 10^{5} \mathrm{pa}, \mathrm{z}(\mathrm{m})$ is the altitude, and $\mathrm{H}_{\mathrm{T}}$ is the scale height (Where $\mathrm{H}_{\mathrm{T}}$ $=8430 \mathrm{~m}) \delta(0.5)$ is the aerosols optical depth value at $\lambda=0.5 \mu \mathrm{m}$. The detailed information about the trend of radiation in each of the selected states in the northern atmosphere of Nigeria was obtained using a graphical method of data analysis. The performance of the models was assessed by plotting beam and diffused radiation and by calculating their mean and standard deviation.

The detailed information about the trend of radiation in each of the selected states in the northern hemisphere of Nigeria was statistically analyzed using the graphical method. Standard statistical packages were used for the statistical analysis of the data collected.

The mean and the standard deviation are used as a measure of dispersion for the estimated data. Mean is the sum of all the observed outcomes (x) divided by the total number of data (n).

$$
\bar{x}=\frac{\left(\sum x\right)}{n}
$$


The standard deviation is a summary measure of the differences of each observation from the mean. The square root of variance is obtained by calculating the difference between each data point and the mean. A low standard deviation means that the data points are close to the set's mean (also known as the anticipated value), whereas a high standard deviation means that the data points are spread out over a wider range of values.

$$
\mathrm{SD}=\sqrt{\frac{\sum(X-\bar{x})^{2}}{n-1}}
$$

\section{Results and Discussion}

The monthly variations of the maximum beam radiation and the minimum diffuse radiation data under the clear sky for the five stations (Kano, Sokoto, Yola, Minna and Maiduguri) in the northern atmosphere are presented in the Table 2 where maximum rad_mb and maximum rad_md represents maximum beam radiation and maximum diffused radiation respectively. Table 3 shows the range of standard deviation for all stations.

Figure 2 shows monthly mean clear sky beam and diffused radiation and monthly mean transmittances of water vapor, ozone, aerosols and gas for the clear sky in Kano for the period of 14 years. Figure 3 shows monthly mean clear sky beam and diffused radiation and monthly mean transmittances of water vapor, ozone, aerosols and gas for the clear sky in Sokoto for the period of 14 years. Figure 4 shows monthly mean clear sky beam and diffused radiation and monthly mean transmittances of water vapor, ozone, aerosols and gas for the clear sky in Yola for the period of 14 years. Figure 5 shows monthly mean clear sky beam and diffused radiation and monthly mean transmittances of water vapor, ozone, aerosols and gas for the clear sky in Minna for the period of 14 years. Figure 6 shows monthly mean clear sky beam and diffused radiation and monthly mean transmittances of water vapor, ozone, aerosols and gas for the clear sky in Maiduguri for the period of 14 years.

Table 2. The maximum beam radiation and the maximum diffuse radiation of the five stations with month.

\begin{tabular}{ccccc}
\hline Stations & Max rad_mb & Month & Max rad_md & Month \\
\hline Kano & 248.9311 & August & 63.8839 & October \\
Sokoto & 245.0264 & April & 66.1272 & September \\
Yola & 262.5472 & April & 58.0912 & January \\
Minna & 251.5264 & April & 62.344 & September \\
Maiduguri & 258.5025 & April & 63.4117 & September \\
\hline
\end{tabular}


Table 3. Range of standard deviation for all stations.

\begin{tabular}{ccc}
\hline Year & Range of rad_mb & Range of rad_md \\
\hline JAN & $1.0-2.0$ & $0.2-0.3$ \\
FEB & $1.5-3.5$ & $0.3-0.6$ \\
MAR & $3.2-18.7$ & $1.0-11.3$ \\
APR & $3.0-16.8$ & $0.5-8.5$ \\
MAY & $1.5-23.2$ & $0.1-11.5$ \\
JUN & $18.0-19.2$ & $0.4-9.6$ \\
JUL & $0.7-16.4$ & $0.1-8.3$ \\
AUG & $0.7-27.5$ & $0.1-14.9$ \\
SEP & $0.6-22.0$ & $0.1-11.1$ \\
OCT & $0.8-19.4$ & $0.1-10.4$ \\
NOV & $1.0-7.0$ & $0.2-0.9$ \\
DEC & $0.9-25.8$ & $0.2-13.9$ \\
\hline
\end{tabular}
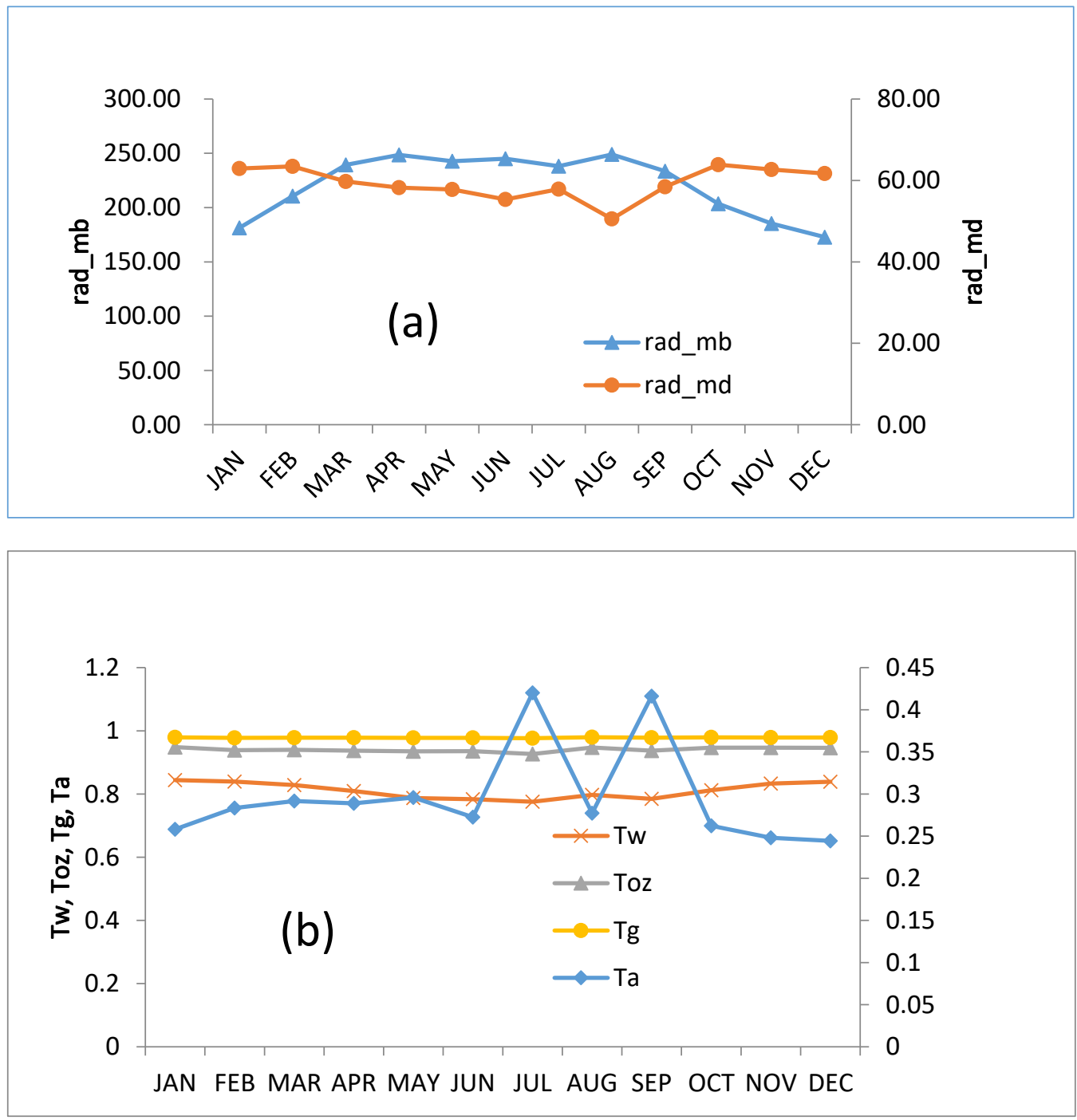

Figure 2. (a) shows Monthly mean clear sky beam (rad_mb) and diffused radiation (rad_md). (b) shows Monthly mean clear sky transmittances of water vapor ( $\mathrm{Tw})$, ozone $\left(\mathrm{T}_{\mathrm{oz}}\right)$, aerosols $(\mathrm{Ta})$ and gas (Ta) in Kano for the period of 14 years(1983-1997). 

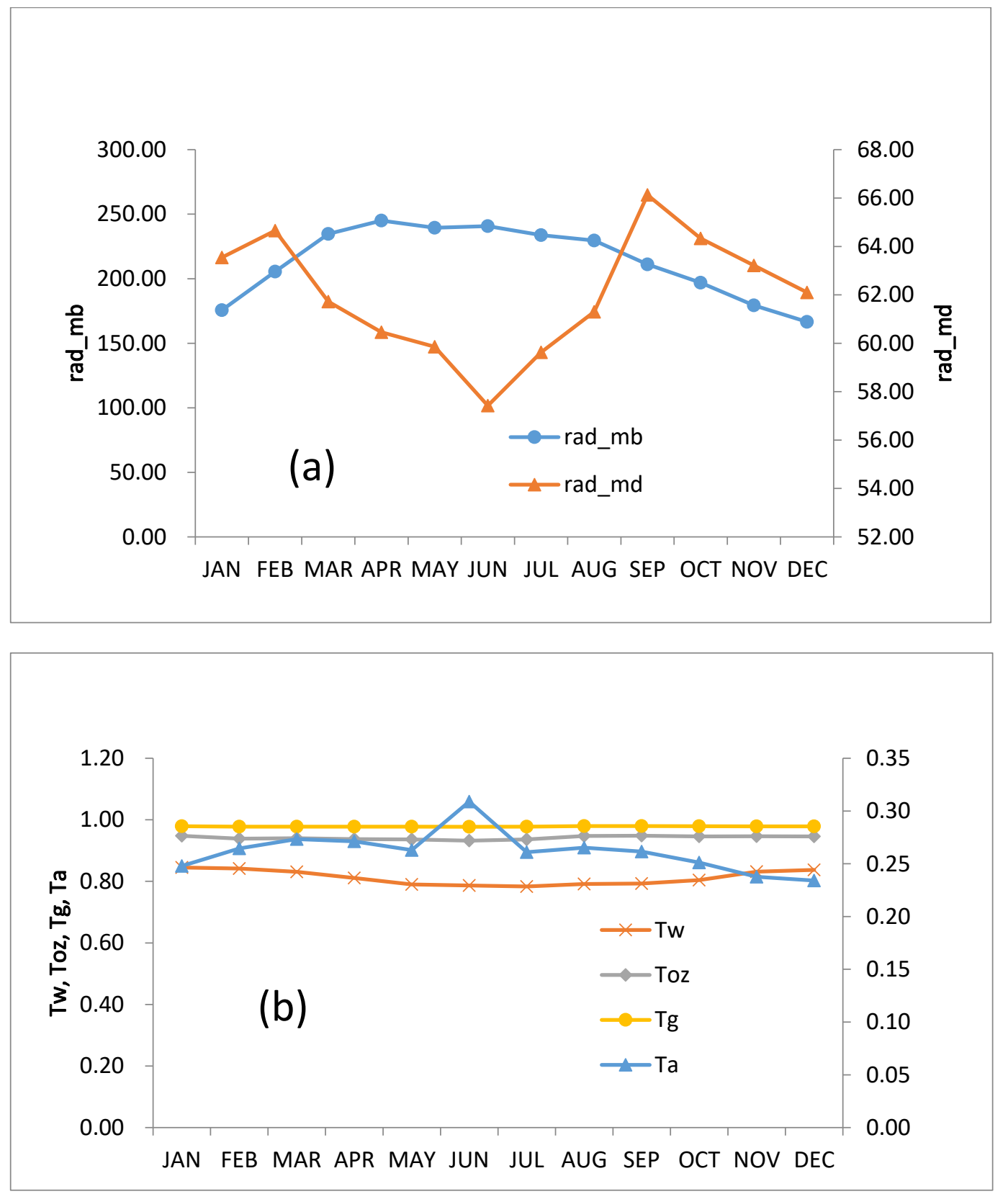

Figure 3. (a) shows Monthly mean clear sky beam (rad_mb) and diffused radiation (rad_md). (b) shows Monthly mean clear sky transmittances of water vapor (Tw), ozone (Toz), aerosols (Ta) and gas (Ta) in Sokoto for the period of 14 years(1983-1997). 

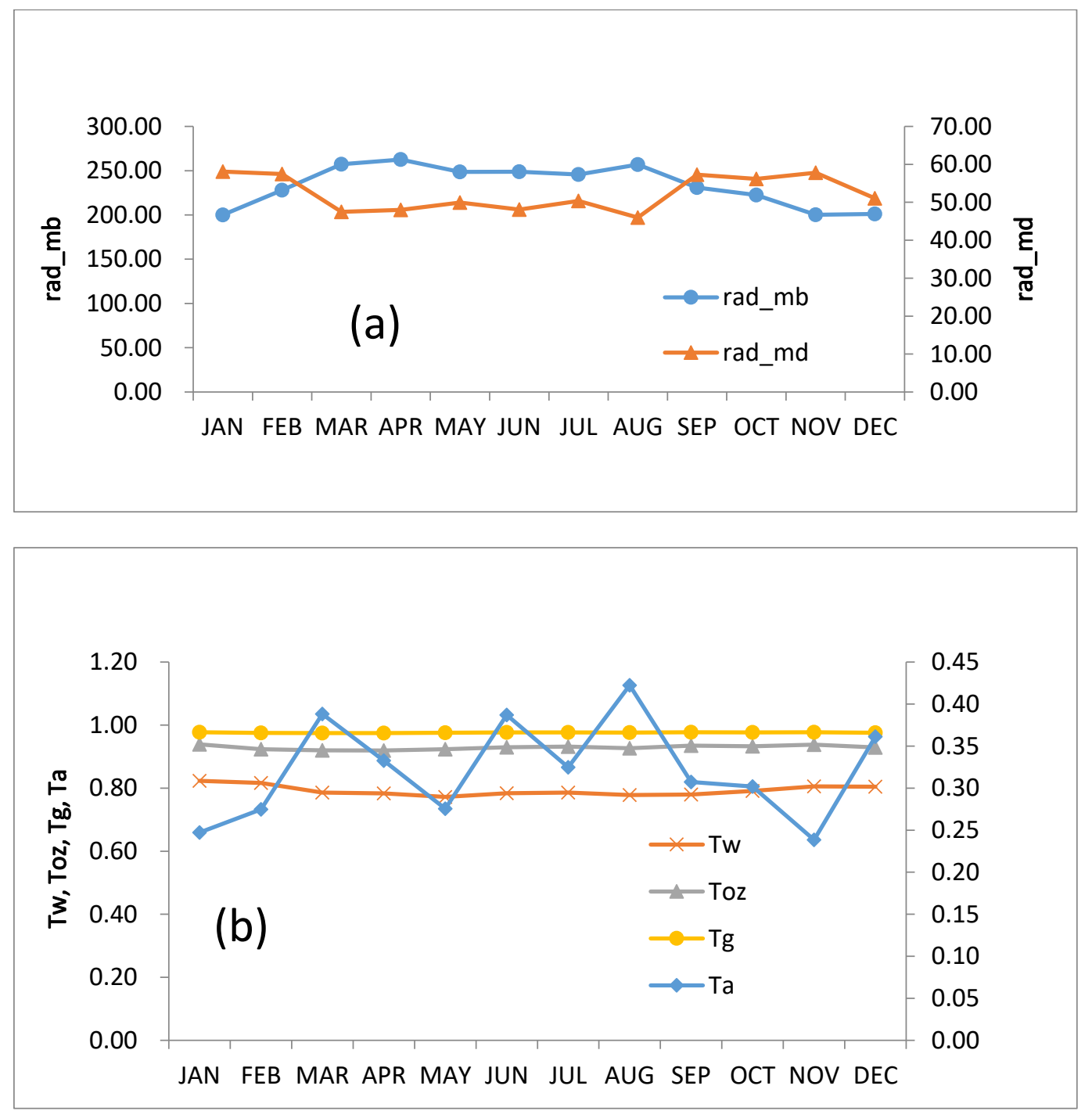

Figure 4. (a) shows monthly mean clear sky beam (rad_mb) and diffused radiation (rad_md). (b) shows monthly mean clear sky transmittances of water vapor (Tw), ozone (Toz), aerosols (Ta) and gas (Ta) in Yola for the period of 14 years(1983-1997). 

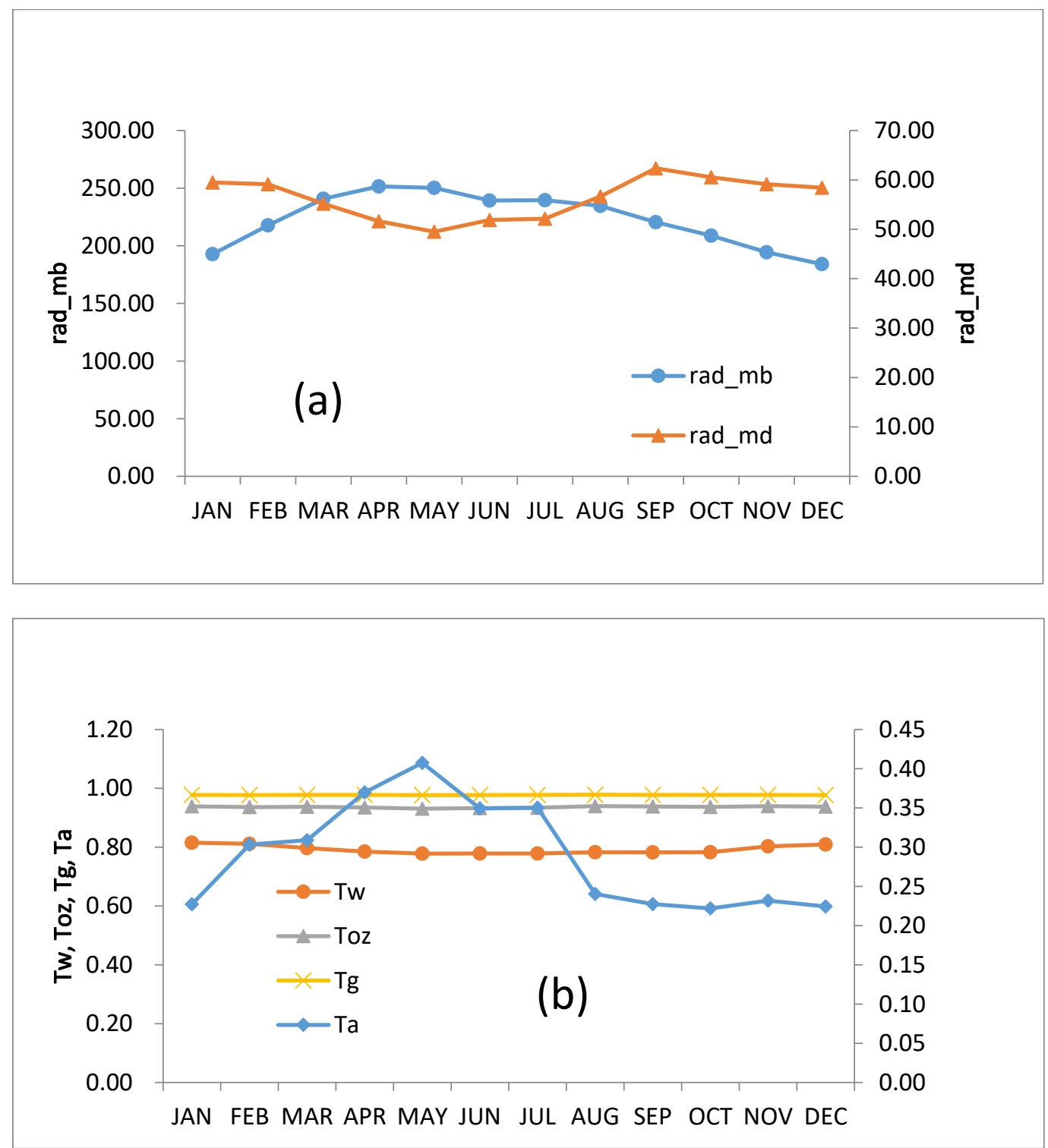

Figure 5. (a) shows monthly mean clear sky beam ( $\mathrm{rad} \mathrm{mb}$ ) and diffused radiation ( $\mathrm{rad} \mathrm{md}$ ). (b) shows monthly mean clear sky transmittances of water vapor (Tw), ozone (Toz), aerosols (Ta) and gas (Ta) in Minna for the period of 14 years(1983-1997). 

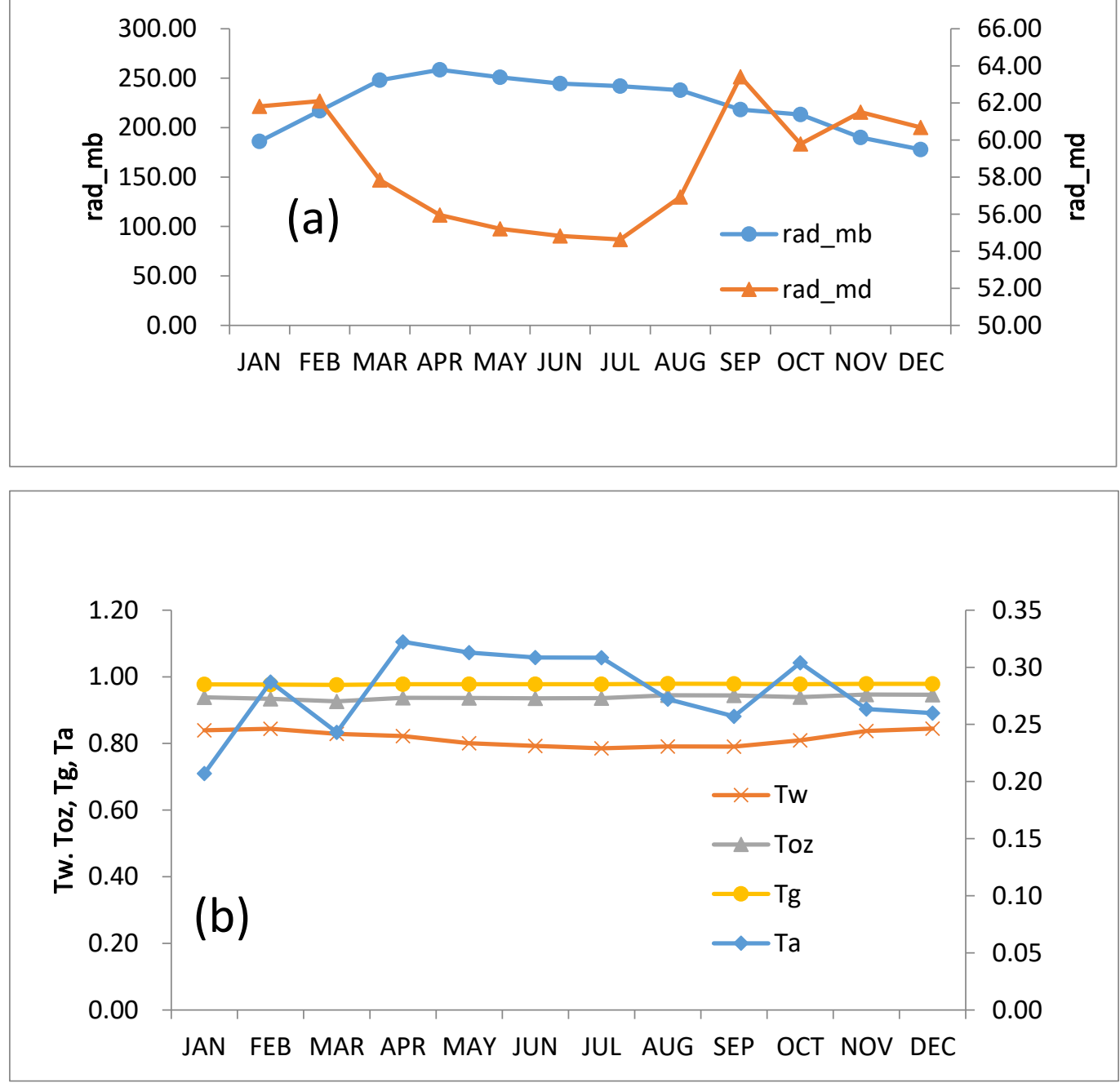

Figure 6. (a) shows monthly mean clear sky beam ( $\mathrm{rad} \mathrm{mb}$ ) and diffused radiation (rad md). (b) shows monthly mean clear sky transmittances of water vapor (Tw), ozone (Toz), aerosols (Ta) and gas (Ta) in Maiduguri for the period of 14 years (1983-1997).

From the graph, Figure 2a shows the beam and diffused radiation under a clear sky in Kano. The beam radiation increases uniformly from January to April and a slight decreases from May to June, it increases again to August and a uniform decreases to December. The maximum beam radiation and minimum diffused radiation is around April to August as shown in Figure 2a. This is because of the atmosphere's degree of radiative transmittances as shown in Figure $2 \mathrm{~b}$. The aerosols transmittance increases from April to September that is, the level of aerosols in the atmosphere decreases from April to September. Water vapor transmittance decreases from April to August. Implying that, the water vapor level in the atmosphere increases from April to August. In the northern atmosphere, the raining season is from June - September and areas we have the highest beam radiation falls within this range, when it rains, aerosols will be washed away and its amount will decrease in the atmosphere thereby positively affecting the percentage increase in the water vapor level in the atmosphere. The water vapor cools the atmosphere in return and absorbs the incoming radiation, but the effect of aerosols absorption is greater than water vapor absorption. Therefore, from April to September more radiation will penetrate the earth's surface. 
Figure 3a shows the beam and diffused radiation under a clear sky in Sokoto. The beam radiation increases uniformly from January to April and a slight decrease from May to June, and a uniform decrease from June to December. The diffuse radiation increases from January to February and decreases from February to June. It increases to September and from September it decreases to December. This is due to the radiative transmittances in the atmosphere. The maximum beam radiation and minimum diffused radiation are around march to August. this is due to the maximum aerosol transmittances are around march to august that is, the aerosol level in the atmosphere is low around March to August and the minimum water vapor transmittances is around March to August as shown in Figure $3 \mathrm{~b}$. This explains that as the level of aerosols in the atmosphere decreases, the level of water vapor in the atmosphere increases.

Figure 4a shows the beam and diffused radiation under a clear sky in Yola. The beam radiation increases uniformly from January to March and a slight decrease and increases within March to August (i.e., in a zigzag manner) and from august it decreases to December. The maximum beam radiation and minimum diffused radiation are around March to August this is as a result of the radiative transmittances in the atmosphere. The highest aerosol transmittances are around March to August (it increases in a zigzag manner) The minimum amount of water vapor is between march to august. This shows that as aerosols decreases in the Atmosphere, the beam radiation increases on earth's surface.

Figure 5 a shows the beam and diffused radiation under a clear sky in Minna in Niger State. The beam radiation increases from April to May, it decreases to June and increases to July, it increases again to August and a uniform decrease to December. The maximum beam radiation and minimum diffused radiation is around April to July and the minimum diffused radiation is in the month of March to July. This occurs as a result of the amount of aerosol extinction in the atmosphere. The highest aerosols transmittance is around April to July and the minimum water vapor transmittance is around April to July as shown in Figure $5 b$.

Figure 6a shows the beam and diffused radiation under a clear sky in Maiduguri. The beam radiation increases from January to April and decreases from April to December while the diffuse radiation decreases from February to July and increases from July to September, but the movement from September to December is in a zigzag manner. The maximum beam radiation is around April to July and the minimum diffuse radiation is also around April to July. This is due to the impacts of radiative transmittances in the atmosphere. The highest aerosols transmittance is around April to July and the minimum water vapor transmittance is around April to August as shown in Figure 6b. That is, between April and July, the concentrations of aerosols in the atmosphere are minimal which results in the estimation of maximum beam radiation and minimum diffuse radiation within April to August. The maximum beam radiation in all stations lies between April to August and the minimum diffuse radiation is around May to August. This is due to the amount of aerosols present and water vapor in the atmosphere. April to August lies within the raining season in the northern atmosphere, aerosols will be washed from the atmosphere, its content reduced and incoming radiation will be absorbed by the few aerosols that is left in the atmosphere therefore maximum beam radiation is estimated within these months. The diffuse radiation is minimum around May to august because the level of aerosols is low within these months, therefore only radiation that is diffused by Rayleigh scattering reaches the earth's surface which is too minimal. This contributes to minimum diffused radiation around April to August. 


\section{Conclusion}

This work presents the approach for estimating the clear sky's normal radiation at the five locations in the northern atmosphere. The Yang model was used to calculate the typical radiation under clear skies on the northern atmosphere using common meteorological parameters. A graphical representation of the estimated radiation in each selected state highlights the significance of beam radiation and shows that the diffused radiation depends on the aerosol's transmittance, water vapor transmittance, Ozone transmittance, gas transmittance and Rayleigh-Scattering. According to the above results, the amount of beam radiation and diffuse radiation reaching the earth's surface under a clear sky in the northern atmosphere is determined by season, the maximum beam radiation and the minimum diffused radiation occur during the raining season and the minimum beam radiation and maximum diffuse radiation occur during the dry season. This is due to aerosols having a greater impact in the northern atmosphere during the dry season and vice versa.. This present work has shown the usefulness of Yang's model in predicting and estimate the monthly mean clear sky normal irradiance for the northern atmosphere in Nigeria. In this sense, the model provides an important background for the estimation of solar radiation component under the clear sky conditions, once an appropriate cloud transmittance parameterization of the atmospheric extinction processes using a simple one band scheme is established. The transparency information has a significant impact in the parameterizations, therefore appropriate information on turbidity conditions should be included. When the hourly information of the Angstrom turbidity coefficients is available, the global irradiance can be estimated with the satisfactory accuracy by using mean hourly value.

\section{References}

[1] H. Moosmu "ller,, R.K. Chakrabarty, W.P. Arnottb, (2009) . A review of Aerosol light absorption and its measurement. Journal of Quantitative Spectroscopy \& Radiative Transfer. 110 844-878

[2] J. C. McVeigh (1977); An Introduction to the Applications of Solar Energy Pergamon Press, - Solar energy - 208 pages

[3] F. S. Johnson, J. D. Purcell, R. Tousey, and N. Wilson (1954), "The Ultraviolet Spectrum of the Sun," in Rocket Exploration of the Upper Atmosphere, ed. R. L. F. Boyd and M. J. Seaton New York: Inter-science Publishers, pp. 279-288. (A survey paper with bibliography)

[4] Javier ALMOROX (2011); Estimating global solar radiation from common meteorological data in Aranjuez Spain. Turk J Phys 35, 53 - 64. c TUB“ ' ITAK doi:10.3906/fiz-0912-20

[5] U. Ali Rahoma (2001); Clearness index estimation for spectral composition of direct and global solar radiations. Applied Energy. Volume 68, Issue 4, Pages 337-346

[6] Leckner, B., 1978. The spectral distribution of solar radiation at the earth's surface-elements of a model. Solar Energy. 20, 143150.

[7] Madkour, M.A., El-Metwally, M., Hamed, A.B., 2006. Comparative study on different models for estimation of direct normal irradiance (DNI) over Egypt atmosphere. Renew Energy. 31, 361-382.

[8] Gueymard, C.A., 2003b. Direct solar transmittance and irradiance predictions with broadband models. Part II. Validation with high quality measurements. Solar Energy. 74, 381-395.

[9] Bird RE, Hulstrom RL. Simplified (1981.) Clear Sky Model for Direct and Diffuse Insolation on Horizontal Surfaces. Golden, Colorado: SERI/TR_642-761.UC-59;61,62,63

[10] Dogniaux R., (1973) Proceedings of the symposium on solar radiation, Smithsonian Institution, Washington, DC; 50-60.

[11] Gueymard C. (1993); Critical Analysis and performance assessment of clear sky solar irradiance models using theoretical and measured data. Solar Energy; 51:121-38

[12] J. F. Orgill and K. G. Hollands T (1977), “Correlation Equation for Hourly Diffuse Radiation on Horizontal Surfaces,". Solar energy, Vol. 19, No. 4, pp. 357-359. doi:10.1016/0038-092X (77)90006-8

[13] Yang, K., Koike, T., Ye, B.,2006. Improving estimation of hourly, daily, and monthly downward shortwave radiation by importing global data sets. Agric. Forest Meteorol. 137, 43-55.

[14] E.J. Batlles, F.J. Olmo, J. Tovar and I. Alados-Arboledas (2000); Comparison of Cloudless Sky Parameterization of Solar Irradiance at Various Spanish Midlatitude Locations. Theoretical and Applied Climatology. Theor. Appl. Climatol. 66.81-93 